\title{
On the concept of equilibrium evaporation and the value of the Priestley-Taylor coefficient
}

\author{
William E. Eichinger ${ }^{1}$ \\ Los Alamos National Laboratory, Los Alamos, New Mexico
}

\author{
Marc B. Parlange ${ }^{2}$ and Han Stricker ${ }^{3}$ \\ Hydrologic Science, University of California, Davis
}

\begin{abstract}
An analytical expression is derived for the Priestley-Taylor coefficient, $\alpha$. This coefficient is generally interpreted as the ratio between the actual evaporation rate and the equilibrium evaporation rate. The derived expression is shown to be equal to the accepted value of 1.26 for typically observed atmospheric conditions and to be relatively insensitive to small changes in atmospheric parameters. A comparison is made between the new expression and data taken over an irrigated field in California. The concept of equilibrium evaporation is called into question and it is suggested that the Priestley-Taylor expression with $\alpha$ equal to 1.26 is a more accurate representation of evaporation under "equilibrium" wet surface conditions.
\end{abstract}

\section{Introduction}

It has been thought theoretically that air passing over a saturated surface will gradually decrease in saturation deficit until an "equilibrium" evaporation rate is reached [Slatyer and McIlroy, 1967; McNaughton, 1976; Monteith, 1981]

$$
L E_{e}=\frac{\Delta\left(R_{\mathrm{nct}}-G\right)}{(\Delta+\gamma)}
$$

where $L E_{e}$ is the equilibrium evaporation rate, $R_{\text {nct }}$ is the net radiative flux, $G$ is the soil heat flux, $\Delta$ is the slope of the saturation vapor pressure curve taken at the temperature of interest, and $\gamma$ is the ratio of the latent heat of vaporization to the specific heat of air at constant pressure (generally taken to be a constant of $0.67 \mathrm{mbar} / \mathrm{K}$ at standard temperature and pressure). However, there is a considerable body of experimental evidence that the evaporation rate is greater than this amount by 20 to $30 \%$. On this basis, Priestley and Taylor [1972] expressed the evaporation rate from an extensive wet surface in the absence of advection as

$$
L E_{a}=\alpha \frac{\Delta\left(R_{\mathrm{ne} 1}-G\right)}{(\Delta+\gamma)}
$$

where $L E_{a}$ is the predicted evaporation rate for a wet surface and $\alpha$ is the Priestley-Taylor coefficient. This coefficient $\alpha$ is generally taken as about 1.26 based upon the average of a number of experimental observations. Since the publication of their paper in 1972, there have been a large number of papers published which report measurements of evaporation from wet or well-watered surfaces that are consistent with this value of

\footnotetext{
'Also at Hydrologic Science, University of California, Davis.

${ }^{2}$ Also at Biological and Agricultural Engineering, University of California, Davis.

${ }^{3}$ Permanently at Department of Water Resources, Wageningen Agricultural University, Netherlands

Copyright 1996 by the American Geophysical Union.

Paper number 95WR02920.

0043-1397/96/95WR-02920\$05.00
}

1.26 [Davies and Allen, 1973; Stewart and Rouse, 1976, 1977; Mukammal and Meumann, 1977; Brutsaert, 1982; Parlange and Katul, 1992]. Although there are some reports of deviations from the value of 1.26 [McNaughton and Black, 1973; Barton, 1979; Shuttleworth and Calder, 1979] and some data to indicate that there may be systematic variations in the value of $\alpha$ with time of day and season of the year [de Bruin and Keijman, 1979], there has been no explanation of why the value should be essentially constant or under what conditions differences from this value of $\alpha$ might be expected.

In this paper we present an analytical expression for the value of $\alpha$ and examine the behavior of this expression for a wide range of situations in the atmosphere in an attempt to understand these observations.

\section{Derivation of the Expression for $\alpha$}

We take the general case of a uniform, saturated surface of large extent, similar to Penman [1948]. Using the definition of the Bowen ratio (the ratio of the sensible heat flux $H$ to the latent heat flux $L E$ ), one may write for the general case

$$
B o=\gamma \frac{\left(T_{s}-T_{a}\right)}{\left(e_{s}-e_{a}\right)}
$$

where $T_{s}$ and $T_{a}$ are the temperatures of the surface and the air, respectively, and $e_{s}$ and $e_{a}$ are the water vapor pressures at the surface and in the air. $T_{a}$ and $e_{a}$ should be referenced to the same height above the surface. If we assume that the slope of the saturation vapor pressure curve at the surface can be approximated by the change in vapor pressure between the surface and the air divided by the change in temperature between the same limits, then

$$
\Delta=\left.\frac{d e^{*}}{d T}\right|_{T} \approx \frac{\left(e_{s}^{*}-e_{a}^{*}\right)}{\left(T_{s}-T_{a}\right)}
$$

where the asterisks on $e_{s}$ and $e_{a}$ signify the saturation vapor pressure at $T_{s}$ and $T_{a}$, respectively. Since the thermodynamic properties of the surface determine the partitioning of energy 

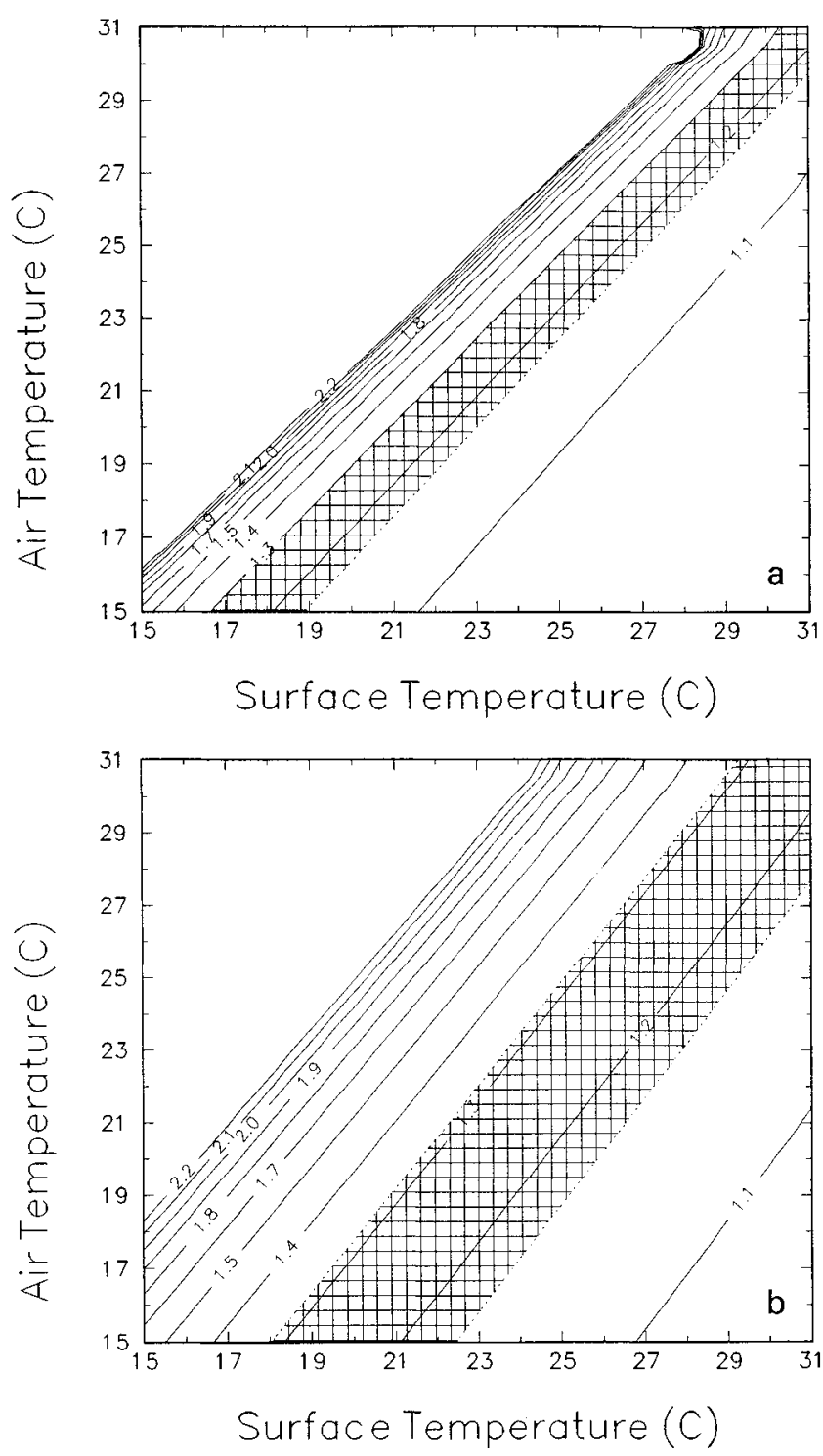

Figure 1. Plot of the predicted value of the Priestley-Taylor parameter $\alpha$ for various surface and air temperatures and relative humidity of (a) $77 \%$ (typical over oceans) and (b) $45 \%$ (typical for land surfaces). The cross-hatched areas are those values of temperature for which $\alpha$ is within about $5 \%$ of the "accepted" value. Note that these areas contain the bulk of the temperatures that one would normally find in the atmosphere for those humidities.

between sensible and latent heats, the slope of the saturation vapor pressure should be evaluated there. It should be noted that this approximation of the slope of the saturation vapor pressure curve is not exact, as was shown by Milly [1991]. However, as long as the temperature difference is not large, the slope of the saturation vapor pressure curve evaluated with $T_{s}$ and $T_{a}$ will be closely approximated (within $4 \%$ ) for most situations by (4). With substitution of (4) into (3), one obtains

$$
B o=\frac{\gamma}{\Delta}\left[1-\frac{\left(e_{a}^{*}-e_{a}\right)}{\left(e_{s}^{*}-e_{a}\right)}\right]
$$

It should be noted that the only assumptions made so far include sufficient upwind fetch, a uniform, saturated surface, and the ability to approximate the slope of the saturation vapor pressure curve with the ambient temperatures and water vapor concentrations. It is at this point that Penman [1948] and later Monteith [1965] developed empirical expressions to deal with the second part of (5). These empirical expressions incorporate wind velocity and, in the case of a less than saturated land surface, surface resistances. Equation (5) is a prediction for the partitioning of energy between latent and sensible heat fluxes that is based upon the thermodynamics of the process.

The expression in (5) should be compared to the PriestleyTaylor expression for the Bowen ratio

$$
B o=\frac{1-\alpha[\Delta /(\Delta+\gamma)]}{\alpha[\Delta /(\Delta+\gamma)]}
$$

The comparison of (5) and (6) yields an expression for the Priestley-Taylor parameter,

$$
\alpha=\frac{1+[\gamma C /(\Delta+\gamma)]}{1-[\gamma C /(\Delta+\gamma)]^{2}}
$$

where

$$
C=\frac{\left(e_{a}^{*}-e_{a}\right)}{\left(e_{s}^{*}-e_{a}\right)}
$$

An examination of (7) shows the insensitivity of the value of $\alpha$ to changes in atmospheric conditions. Given that the experimentally determined value of $\alpha$ is about 1.26 , the squared term in the denominator will be small, about 0.05 , leaving the denominator relatively constant and near the value of 1 . Thus the bulk of the variation in $\alpha$ must come from the second part of the numerator of (7), which is insensitive to small changes in temperature or humidity. Figures $1 \mathrm{a}$ and $1 \mathrm{~b}$ are plots of the values of $\alpha$ for various surface and air temperatures for relative humidity (RH) of $77 \%$ (typical for oceans) and $45 \%$ (typical for a semiarid land surface). While there are variations in the values, the value of $\alpha$ for most commonly encountered situations is about 1.26. For example, in the $77 \%$ RH case, the calculated value of $\alpha$ is within $5 \%$ of 1.26 for a range of temperatures in which the air temperature over the surface is about $0.75^{\circ}$ to $2.75^{\circ} \mathrm{C}$ less than the surface temperature. Under normal conditions in the tropical oceans, the air temperature is from 0.9 to $1.5^{\circ} \mathrm{C}$ cooler than the ocean surface. Similarly, for the $45 \% \mathrm{RH}$ case the calculated value for $\alpha$ is within $5 \%$ of 1.26 for situations where the air temperature is between $2^{\circ}$ and $7.5^{\circ} \mathrm{C}$ less than the surface temperature. This again is within normal temperature variations over land surfaces based upon measurements made about $1 \mathrm{~m}$ above the surface. For wellwatered surfaces in arid climates, a stable atmospheric stability condition often develops in which the surface temperature is less than that of the ambient air. Under such circumstances, (7) and (8) will predict the correct value for $\alpha$, but the values will be greater than 1.26. Significant deviation from 1.26 should be expected for situations such as this which are far from equilibrium. The point is that for conditions that are commonly encountered, the value of $\alpha$ is near 1.26 especially over the ocean with its long fetch over a saturated surface. There are clearly situations in which the value may depart significantly from 1.26 , but they are the exception.

For completeness, a form of the equation for $\alpha$ may be written for the case when the surface is not saturated. For this case, (7) remains the same, with $C$ now expressed as

$$
C=\frac{\left(1-R H_{a}\right) e_{a}^{*}-\left(1-R H_{s}\right) e_{s}^{*}}{\left(R H_{s} e_{s}^{*}-e_{a}\right)}
$$


where $R H_{s}$ and $R H_{a}$ are the relative humidity of the surface and the air respectively. Note that in the case of a saturated surface the expression reduces to (8). For a nonsaturated surface the right side of the numerator in (9) acts to reduce the magnitude of $C$, thus reducing the magnitude of $\alpha$ and thus reducing the magnitude of the latent energy flux with respect to the sensible heat flux. In the limit of a hot, arid surface, $C$ can be negative, and thus $\alpha$ can be less than 1.0. This is in contrast to the normal reasoning that a cannot be less than 1 [Priestley and Taylor, 1972]. Indeed, that $\alpha$ is less than 1 is indicative of a relatively hot, dry surface.

\section{Comparison With Data}

An examination of data obtained at the Campbell tract at the University of California, Davis, was undertaken to study this formulation of the Priestley-Taylor $\alpha$. The data and field measurements are described in detail by Katul and Parlange [1992]. The evaporation rate was examined for an irrigated bare soil surface for the 2 days following several irrigations. Evaporative fluxes, soil and air temperatures, soil heat flux, net radiation, horizontal wind speed, and relative humidity were measured over 20 -min averages for those days. With the exception of wind speed at $2 \mathrm{~m}$ and soil heat flux, measurements were made at a height of $0.8 \mathrm{~m}$. Irrigation was conducted for 4 to 5 hours on the night before the measurement period in order to sufficiently saturate the surface. All the available data from days 257, 258,271,272, 279, 280, 286, 287, and 297 of 1990 were used in the analysis. Predictions based upon (2) and (7) were made using surface and air measurements, as well as net radiation and soil heat flux measurements, and compared to the evaporation measured with a weighing lysimeter.

Figure 2 is a presentation of the evaporative flux comparison based on this analysis. Typically, the $\alpha$ values centered around 1.26 , with an increase in the afternoon to a maximum of about 1.5. The slope of the regression line $(0.99 \pm 0.02)$ and the correlation coefficient $\left(r^{2}=0.88\right)$ indicate a good fit of predicted evaporation versus measured evaporation. The average error of the estimate differs from the measured by about 52 $\mathrm{W} / \mathrm{m}^{2}$; this is of the order of the estimated lysimeter uncertainty [Katul and Parlange, 1992].

\section{Discussion}

Since atmospheric processes act to maintain air temperatures and relative humidities such that $\alpha$ remains near 1.26 over saturated surfaces, this, rather than $\alpha$ equal to 1.0 , should be considered the "equilibrium" wet surface evaporation value. The value of $\alpha$ equal to 1.0 over a saturated surface requires that the air also be saturated, a condition that is rarely found in nature. In fact, the atmosphere is not in an "equilibrium" state when $\alpha=1.0$, since it implies an artificially closed top atmospheric boundary layer (ABL). Brutsaert [1982, p. 220] notes that "conditions in the sense of Slatyer and Mcllroy $(\alpha=$ 1.0) hardly ever occur" and concludes that mixing in the ABL is the cause of the evaporation in excess of that predicted by (1). Both Slatyer and McIlroy [1961] and McNaughton [1976] used a "lidded" ABL model, and the equilibrium evaporation condition reached, for wet surfaces, was saturation of the air, with a corresponding evaporation rate given by (1). The "excess" evaporation is due to the vertical transport of heat and water vapor, which incorporates entrainment of relatively drier free atmosphere air at the top of the ABL. De Bruin [1983]

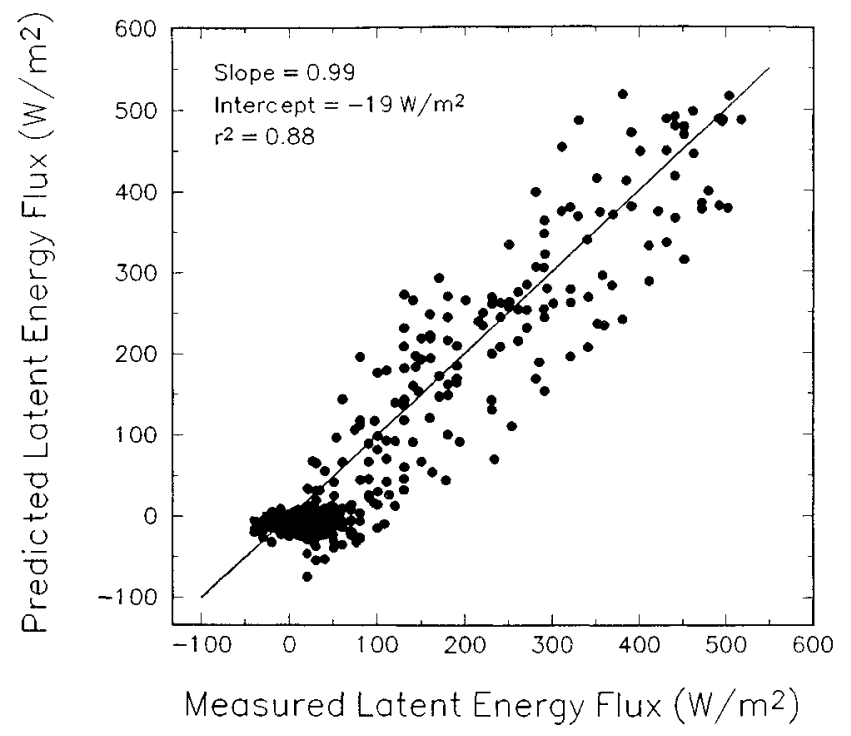

Figure 2. A plot of the predictions for evaporation based upon (7) and (2) versus the lysimeter-measured evaporation over an irrigated, bare soil field. Five irrigations were carried out in 1990. The data includes the 2 days following each irrigation (except the last for which no data were available). The average error in the estimate is $52 \mathrm{~W} / \mathrm{m}^{2}$.

developed a model including entrainment at the top of the boundary layer and obtained values for $\alpha$ near 1.26. That heat and water vapor are transported through this boundary and higher up into the troposphere precludes the existence of saturated atmospheric equilibrium conditions. Note that over the tropical Pacific Ocean, with $1000 \mathrm{~km}$ of fetch, a saturated atmosphere is never reached.

\section{Conclusion}

An analytical expression for the value of the Priestley-Taylor "constant" $\alpha$ has been presented. This expression can be used to obtain the typically observed value of this parameter (1.26) for wet surfaces. The fact that there is a relatively narrow range of existing Earth-atmospheric conditions leads to a nearly constant $\alpha$ value for most wet surfaces observed on the Earth. It is suggested that the real "equilibrium" wet surface evaporation is defined by the Priestley-Taylor model.

Acknowledgments. This work was performed as part of and funded by the DOE GEONET program, the INCOR Program, the California State Salinity Drainage Task Force, Water Resources Center, the USGS-USDI, and the National Science Foundation. The thoughtful comments of three anonymous reviewers are greatly appreciated. The assistance of many individuals in these programs is gratefully acknowledged. Our colleagues Gabriel Katul and Mike Mata helped obtain the meteorological data and are gratefully acknowledged.

\section{References}

Barton, I. J., A parameterization of the evaporation from a nonsaturated surface, J. Appl. Meteorol., 18, 43-47, 1979

Brutsaert, W., Evaporation Into the Atmosphere, D. Reidel, Norwell, Mass., 1982.

Davies, J. A., and C. D. Allen, Equilibrium, potential, and actual evaporation from cropped surfaces in southern Ontario, J. Appl. Meteorol., 12, 649-657, 1973.

de Bruin, H. A. R., A model for the Priestley-Taylor parameter $\alpha, J$ Clim. Appl. Meteorol., 22, 572-578, 1983. 
de Bruin, H. A. R, and J. Q. Keijman, The Priestley-Taylor model applied to a large shallow lake in the Netherlands, J. Appl. Meteorol., $18,898-903,1979$

Katul, G. G., and M. B. Parlange, A Penman-Brutsaert model for wet surface evaporation, Water Resour. Res., 28, 121-126, 1992.

McNaughton, K. G., Evaporation and advection, Q. J. R. Meteorol. Soc., 102, 181-191, 1976.

McNaughton, K. G., and T. A. Black, A study of evapotranspiration from a Douglas fir forest using the energy balance approach, Water Resour. Res., 9, 1579-1590, 1973.

Milly, P. C. D., A refinement of the combination equations for evaporation, Surv. Geophys., 12, 145-154, 1991.

Monteith, J. L., Evaporation and Environment, Symp. Soc. Exp. Biol., 19, 205-234, 1965.

Monteith, J. L., Evaporation and surface temperature, Q. J. R. Meteorol. Soc., 107, 1-27, 1981.

Mukammal, E. I., and H. H. Neumann, Application of the PriestleyTaylor evaporation model to assess the influence of soil moisture on the evaporation from a large weighing lysimeter and class A pan, Boundary Layer Meteorology, 14, 243-256, 1977.

Parlange, M. B., and G. G. Katul, Estimation of the diurnal variation of potential evaporation from a wet bare-soil surface, J. Hydrol., 132, $71-89,1992$.

Penman, H. L., Natural evaporation from open water, bare soil, and grass, Proc. R. Soc. London A, 193, 120-145, 1948.
Priestley, C. H. B., and R. J. Taylor, On the assessment of surface heat flux and evaporation, Mon. Weather Rev., 106, 81-92, 1972.

Shuttleworth, W. J., and I. R. Calder, Has the Priestley-Taylor equation any relevance to forest evaporation?, J. Appl. Meteorol., 18, $639-646,1979$

Slatyer, R. O., and I. C. McIlroy, Practical Microclimatology, Commonwealth Scientific and Industrial Research Organisation, Melbourne, Victoria, Australia, 1967.

Stewart, R. B., and W. R. Rouse, A simple method for determining the evaporation from shallow lakes and ponds, Water Resour. Res., 12, 623-628, 1976

Stewart, R. B., and W. R. Rouse, Substantiation of the Priestley-Taylor parameter $\alpha=1.26$ for potential evaporation in high latitudes, $J$. Appl. Meteorol., 16, 649-650, 1977.

W. E. Eichinger, Los Alamos National Laboratory, Mail Stop K300, Los Alamos, NM 87545.

M. B. Parlange and H. Stricker, Hydrologic Science, University of California, Davis, CA 95616.

(Received December 28, 1994; revised September 6, 1995; accepted September 20, 1995.) 